\title{
Ethical dilemmas experienced by occupational therapy students - the reality
}

\author{
N Nortjé, ${ }^{1}$ DPhil; J de Jongh, ${ }^{2} \mathrm{PhD}$
}

${ }^{1}$ Department of Dietetics, Faculty of Community and Health Sciences, University of the Western Cape, Bellville, South Africa

${ }^{2}$ Department of Occupational Therapy, Faculty of Community and Health Sciences, University of the Western Cape, Bellville, South Africa

Corresponding author: N Nortjé(nnortje@uwc.ac.za)

Background. Ethics training strives to facilitate critical thinking, objective analysis and clinical reasoning skills to equip students with the ability to make an impartial and unbiased decision in different contexts and diverse client populations. This enhances students' learning experiences. Occupational therapy (OT) students are expected to work in a variety of contexts. They experience many sources of conflict in their fieldwork practice on a daily basis, while at the same time upholding professional values, responsibilities and duties.

Objectives. To determine the issues that students face in their fieldwork practice and address these in an ethical manner.

Methods. Qualitative research was done among fourth-year OT students by means of an open-ended questionnaire.

Results. Three major themes relevant to ethical issues were identified: professional-student relationship; professional boundaries; and disclosure of information and keeping information confidential.

Conclusion. The salient themes identified reflect the primary ethical tensions in the international literature from the UK and Canada, but little evidence has been reported from South Africa. Taking cognizance of this, those who are involved in the training of healthcare professionals should incorporate the identified issues in the class discussions. For many students their fieldwork practice may be their first experience with some of the aforementioned issues. Alluding to these in a safe environment (class situation) and equipping the students with a framework of analysis are very important.

Afr J Health Professions Educ 2015;7(2):187-189. DOI:10.7196/AJHPE.396

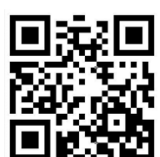

Ethics in healthcare is an important determinant of the professional outcomes for occupational therapists' daily professional practice. ${ }^{[1]}$ The Health Professions Council of South Africa (HPCSA) places great emphasis on ethical behaviour towards clients and expects registered professionals to act accordingly ${ }^{[2]}$ Occupational therapy (OT) students are expected to work in a variety of contexts and they experience many sources of conflict in their fieldwork practice on a daily basis, while at the same time upholding professional values, responsibilities and duties. This conflict results in ethical dilemmas, such as when an individual faces two or more equally stressful alternatives that are mutually exclusive. ${ }^{[3]}$ According to Pauly et al.,$^{[1]}$ moral conflict is closely associated with the ethical dimensions of practice. In accordance with the Occupational Therapy Professional Board's Minimum Standards for the Training of Occupational Therapists, the curricula should include ethics as part of the undergraduate training programme ${ }^{[4]}$ Research indicates that OT students are mostly aware of the correct course of action, but often feel constrained to act in another way as a result of institutional and/or societal rules. ${ }^{\left[{ }^{[5]}\right.}$

Ethics training strives to facilitate critical thinking, objective analysis and clinical reasoning skills to equip students with the ability to make an impartial and unbiased decision in different contexts and diverse client populations, which enhances students' learning experiences. ${ }^{[6]}$ Ethical training is guided by a consequential framework, where the outcome should guide the behaviour of clinicians, or a rule-based (deontological) approach, where rules (i.e. codes of ethics) should guide the conduct of a professional. According to the HPCSA's sub-committee, ethics training should focus on a careful and systematic reflection of the analysis of moral discussions and behaviour in the healthcare environment, ${ }^{[1]}$ which is a hybrid between the aforementioned approaches.
Metz $^{[7]}$ makes an interesting statement by arguing that ' $\ldots$. [ $t$ ]oday's dilemmas make tomorrow's rules'. As ethics evolves over time, the challenges currently faced by professionals and the decisions they make accordingly, become the standard of future practice. Therefore, it is imperative for healthcare educators to understand the issues students face in their everyday fieldwork practice and equip them to deal with these ethical issues.

\section{Objectives}

The objective of this research was to determine the issues that students face in their fieldwork practice and address these in an ethical manner.

\section{Methods}

As the aim of the study was to hear the voice of the student, it was decided to use qualitative methodology, where the focus is not on refining any hypothesis, but on a narrative investigation into the field of experience of the research participants. A non-probability sampling technique was used by interviewing a cohort of 30 final-year OT students from a university in South Africa (SA). As this study is exploratory, purposive sampling was employed, where certain individuals with specific experiences were identified. ${ }^{[3]}$ The inclusion criteria were the following: English speaking; OT final-year student; student registration with the HPCSA; registration at a SA university.

Data were collected using an open-ended questionnaire. No individual was coerced into completing the questionnaire and all students were assured that they could leave the study at any time. Anonymity was ensured - no personal identifiers were recorded (i.e. name, surname or student number). The study protocol received ethics approval.

As the aim of qualitative research is not to make a statistical generalisation to any population beyond the sample surveyed, no control group was 
included in the study. The reliability or consistency of the data analysis in qualitative research is an evolving process, and the interpretation thereof can differ vastly. ${ }^{[7]}$ The authenticity of the data is very important, which refers to the concept that a fair, honest and balanced account of social life - from the viewpoint of someone who lives through it daily ${ }^{[8]}$ - has been given.

Qualitative data analysis is generally based on organising the data into categories based on themes and coding the latter to derive salient themes. This is achieved by organising the data into categories by using themes and concepts. In this study, the participants' answers were coded using an opencoding technique, where general themes were identified and each answer was coded accordingly. Once the first round of coding was complete, a second round was conducted, i.e. axial coding. During this phase, the researchers organised the themes and coded each into subthemes to ascertain whether or not there were any relationships between subthemes from the initial opencoded themes. Once all subtheme relationships were identified, a final round of coding took place, whereby selective coding was performed and salient themes were identified, together with any subtheme relationships. These, as well as the final salient themes, are presented in the results section.

\section{Results}

This section reports on the most significant themes identified after the data were analysed by applying the methodology discussed above. Three major themes relevant to ethical issues were identified and are presented below to give voice to the students and illustrate the meaning.

\section{Professional-student relationship}

For many students an ethical dilemma occurs when they are unsure how to approach a situation where they disagree with a qualified OT with regard to an alternative form of therapy they believe is in the best interest of the client. Students often feel that they do not have the authority to approach a senior staff member (or report them in severe cases) and cannot question the behaviour of qualified therapists, as it could possibly cause tension and even impact negatively on their results/reports. One student observed:

'While doing practical I built up good interpersonal relationships with the staff and clients. However, just before mid-practical evaluation, my supervisor called me in to discuss a complaint that she has received from the clinician at the placement. The clinician asked the supervisor to inform me that I was not behaving in a professional manner (I was too friendly with the clients) and that I needed to tone down my friendliness. This was discouraging and impacted negatively on my group sessions. I had difficulty to decide whether to be true to myself and behave the way I did initially in order to maintain good interpersonal relationships with the group members and ensure effective intervention or do what the clinician said in order not to be marked down on professional behaviour.

\section{Professional boundaries}

Being in a caring profession, where students frequently are confronted with the vulnerabilities of clients, it is often difficult to distinguish between professional and unprofessional behaviour. Furthermore, because the student often also engages with clients on a personal level, the latter feel they can trust the students and will often share information that could be deemed as outside the scope of practice. This conduct is in itself not commendable, as it contravenes the boundaries of a professional therapeutic relationship. However, as students are still learning about these boundaries, they are often hesitant to be firm because they are afraid it would impact negatively on their relationship, resulting in clients taking advantage of them. The following is an example of such an issue, as highlighted by a student:

'During fieldwork I was required to build relationships with clients. I was able to build extremely good interpersonal relationships with all my clients however with one of my clients it became uncomfortable. He asked me if I could bring him DVDs to watch as it was boring at the rehabilitation centre. I did so and we built up a good relationship with each other, however he kept asking me to bring him things such as food. I knew that I needed to draw the line, but was cautious as it would affect our relationship with each other'.

\section{Disclosure of information and keeping information confidential}

Students are often in despair as they are not sure what to do with confidential information that other members of the multidisciplinary team have shared with them. The following illustrates the issue:

'During my placement at a school there was one particular teacher that I worked closely with as I saw individual clients from her class as well as ran groups with the learners. Often the teacher would speak about the learners in an inappropriate manner, making fun of them, openly disclosing information or just speaking about them in a negative manner. It was difficult for me to know what to do.'

Furthermore, the students are uncomfortable with the places where and manner in which the information-sharing happens - often in non-private settings such as hallways or classrooms. Most students are aware of their duty to protect client confidentiality, and often witness how other members of the healthcare professions team show a lack of respect for client confidentiality.

'As I worked in a multidisciplinary team at a drug rehab centre a nurse (whose consulting rooms were next to my office) was seeing one of the clients and she was scolding her about having a sexually transmitted infection (STI) and that she should not be having sex because she is still a minor. The nurse also accused the client of "sleeping around" and stated that it was the reason why she had the STI. Unfortunately, the nurse did not close the door while she was speaking to the client and almost all of the male clients at the rehabilitation centre, who were coming from a group session with the counsellor, had heard the nurse disclose this client's illness and because she did not close the door, the male clients were also able to see who the client was - therefore putting her at risk. This made me feel uncomfortable as I was unsure how to handle the situation.'

\section{Discussion}

The salient themes identified by this study echo the primary ethical tensions seen in the international literature from the UK and Canada, ${ }^{[9,10]}$ but little evidence has been reported from SA.

This discussion adopts a critically reflective position to contemplate the described experiences of students in light of peers from the UK and Canada and to participate in a discussion about the consequences for professional practice, educational reforms, and policy issues. The findings highlight the salient themes of ethical dilemmas that OT students face during fieldwork practice. These ethical issues will be employed to inform a framework that could be used to assist them in their ethical reasoning process. The aim of any framework is to create critical thinking, where nothing should be taken for granted; instead, the practitioner should ask critical questions about conventions, opinions and sentiments and ultimately be aware of incorrect reasoning that could influence the practitioner in accepting positions that are not supported by analytical arguments and evidence. 


\section{Professional-student relationship}

For most of the students conflict arose when there was a difference of opinion that contributed to moral differences. The sensitivity of the students towards the issue could be the result of the ethics training that they received.They consequently know what to expect of the different role players in the therapeutic setting.

Moral differences are often difficult for students to understand as they might not have had exposure per se to similar circumstances to ascertain the correct way to behave in such situations. In an attempt to address this, we draw on the work of Immanuel Kant, who developed the obligation-based theory in which he argues that one should rest one's moral judgements on reasons that also apply to others who are similarly positioned. ${ }^{[11]}$ Therefore, the ability to make a moral decision should be guided by a combination of practical reasoning (experience) and pure reasoning (not having had any experience). However, the act should be guided by what Kant calls a universal maxim/imperative, which states that one's behaviour in a situation should be of such a manner that, should it become universally applicable, it would be to the benefit of humanity at large. ${ }^{[12]}$ The focus of deontology is not the end result of an action, but rather whether the action itself is morally acceptable. Through applying this framework, the students should soon realise that what is good is not always right and what is bad is not always wrong.

Being able to take this metaposition will enable students to deal with issues of conflicting value systems. When students feel that the opinion of their senior is not morally justifiable (applying Kant's universal maxim) they should report the behaviour, even though the outcome could potentially be negative.

\section{Professional boundaries}

Allan ${ }^{[13]}$ defines a boundary as 'an imaginary line between behaviour that is generally appropriate when a therapist acts in a professional capacity, and behaviour that is not. Similar to Kant's assertion that experience is a guiding factor in moral behaviour, the same applies to setting boundaries. As boundary setting is very subjective and influenced by factors such as public morality, professional standards and culture, a feeling of unease will develop with a young practitioner if his/her boundaries have been crossed. The HPCSA's guidelines assist practitioners in drawing boundaries by advising who should not be treated (i.e. family members, friends, people bringing gifts). The setting of boundaries assists the young practitioner to conduct therapy professionally, creates safe environments for clients and sets parameters within which services are delivered. The primary concern in establishing and managing boundaries with clients must be in the best interests of the client. Students should be careful not to disclose too much personal information (e.g. personal cell phone number); self-disclosure should be well considered and the motivation of such disclosure should be well examined.

Another important aspect of drawing boundaries is guided by the clothing a practitioner wears. Research indicates that a person's clothing may convey a very powerful symbolic message. ${ }^{[14]}$ As a general guiding rule, clothing should be neat but conservative and always take the work environment into account.

\section{Confidentiality}

There seem to be inconsistencies in the students' understanding of privacy and confidentiality. Although the two are very closely linked, there are distinct differences. Privacy refers to the notion of access to others, whereas confidentiality is restricted to information, how it relates to accessing such information and how it is applied. ${ }^{[15]}$
Confidentiality is not only an ethical principle, as enshrined in the principle of respect of autonomy, ${ }^{[12]}$ but is also addressed by the HPCSA's Guidelines for Good Practice in the Health Care Professions. ${ }^{[16]}$

Brody ${ }^{[17]}$ argues that confidentiality is central to preserving the human dignity of clients and that patient autonomy (concept of self-rule, where clients are informed) should always be considered. Therefore, it is unethical for members of the healthcare team to discuss clients' information outside a clinical setting; they should refrain from doing so.

\section{Strengths and limitations}

The strengths of this study include the importance and veracity of actual accounts of students' ethical experiences, the extent to which similar themes occurred among the participants, and the possibilities that the study opens for further research and education.

Limitations of this study include the limited generalisation of the results and the geographical representation of the participants, as the research was conducted only at one institution in SA.

\section{Conclusion and recommendations}

This article highlights the complex ethical dynamics that students experienced in fieldwork practice. They were taught some basic ethics, which might have sensitised them to the issues identified above. Taking cognizance of this, those who are involved in the training of healthcare professionals should incorporate the identified issues in class discussions. For many students, their fieldwork practice may be their first experience with many of the abovementioned issues. Alluding to these in a safe environment (class situation) and equipping the students with a framework of analysis are very important. Once the students have the ability to objectively remove themselves from a specific situation and realise that the focus of the case should not be themselves but rather the patients/ clients and the benefit of the latter, then only will they be able to apply their critical thinking abilities. Formal classroom time should be spent on creating critical thinking abilities, simulating as many situations as possible and alluding to the difference in people's ethical and moral reasoning abilities, which should be taken into consideration when applying the skills the students are taught. Furthermore, educators should realise the importance of listening to the voice of the students and learn from the students' experiences as they inform where there is a need to address certain issues. Collaboratively, this could contribute to the quality of ethics education and services rendered by healthcare professionals.

\section{References}

1. Pauly BM, Varcoe C, Storch J. Framing the issues: Moral distress in health care. HEC Forum 2012;24:1-11.

2. Health Professions Council of South Africa (HPCSA). Proposed Core Curriculum on Human Rights, Ethic and Medical Law for Health Care Practitioners. 2006. http://www.hpcsa.co.za/downloads/radiography/core curriculum_on_human_rights_ethics_and_medical_law.pdf (accessed 10 February 2014).

3. Nortjé N. Ethical tensions faced by dietetic students during fieldwork. S Afr J Clin Nutr 2014;27(3):128-131 4. Health Professions Council of South Africa (HPCSA). Professional Board for Occupational Therapists, Medical Orthotics Prosthetics and Arts Therapy. Minimum Standards for the Training of Occupational Therapists. Pretoria: HPCSA, 2009. Atwal A, Caldwell K. Ethics, occupational therapy and discharge planning: Four broken principles. Australian Occupational Therapy Journal 2003;50(4):244-251

6. Diab P, Naidu T, Gaede B, Prose N. Cross-cultural medical education: Using narratives to reflect on experience. Afr J Health Professions Educ 2013;5(1):42-45. [http://dx.doi.org/10.7196/AJHPE.234]

7. Metz MJ. Some ethical issues related to hearing instrument dispensing. Seminars in Hearing 2000;21(1):63-74 8. Neuman WL. Basics of Social Research - Qualitative and Quantitative Approaches. 2nd ed. Boston: Pearson, 2007:108-139.

9. Barnitt R. Ethical dilemmas in occupational therapy and physical therapy: A survey of practitioners in the UK NHS. J Med Ethics 1998;24:193-199.

10. Kinsella EA, Park AJ, Appiagyei J, Chang E, Chow D. Through the eyes of students: Ethical tensions in occupational therapy practice. Revue Canadienne D’Ergotherapie 2008;75(3):176-183.

11. Beauchamp TL, Childress JF. Principles of Biomedical Ethics. 5th ed. New York: Oxford University Press, 2001.

12. Kant I. Groundwork for the metaphysics of morals. In: Nadelhoffer T, Nahmias E, Nichols S, eds. Mora Psychology - Historical and Contemporary Readings. Chichester, UK: Wiley Blackwell, 2010.

13. Allan A. The Law for Psychotherapists and Councellors. 2nd ed. Somerset West: Inter-Ed Publishers, 2001.

14. Allan A. Law and Ethics in Psychology: An International Perspective. Somerset West: Inter-Ed Publishers, 2008.

15. Sim J. Client confidentiality: Ethical issues in occupational therapy. Br J Occupational Ther 1996;59(2):56-61.

16. Health Professions Council of South Africa (HPCSA). Guidelines for Good Practice in the Health Care Professions - Confidentiality: Protecting and Providing Information (Booklet 10). Pretoria: HPCSA, 2008.

17. Brody H. The physician/patient relationship. In: Vearch RM, ed. Medical Ethics. Boston: Jones and Barlett, 1990. 